\title{
Design and Optimization of Front Underrun Protection Device
}

\author{
Dr. T. Ramamohan $\mathrm{Rao}^{1}$, A. Rama Krishna ${ }^{2}$ \\ ${ }^{I}$ (Professor Mechanical Department, Vasavi College of Engineering/ Osmania University, India) \\ ${ }^{2}$ (Student Mechanical Department, Vasavi College of Engineering/ Osmania University, India)
}

\begin{abstract}
Front Under run Protection Device is tested for car occupant safety by performing Crash analysis with $800 \mathrm{~kg}$ (mass of the car) hitting the Front Underrun Protection Device with certain velocity and analyzing its performance and changing design to improve the crash results. Optimization is carried out to improve the crash results for safety of passenger. To reduce number of iterations during the development process, the computational simulation method is used in Front Underrun Protection Device analysis for impact loading. An explicit finite element code like LS Dyna is used for the simulation. This paper explains the FE analysis of Front Underrun Protection Device for impact loading. All the results obtained from the CAE analysis are evaluated against the requirements of IS 14812-2005 which could reduce the process development time and cost. Unigraphics(NX.8) for modeling Front Underrun Protection Device and Preprocessing in Hypermesh and LS DYNA for Crash Analysis (solving), results are viewed in Hyper view.Altair Optistruct is used for weight reduction and change in design of Front under run protection device.
\end{abstract}

Keywords: Under-run Protection Device, LS Dyna, CAE Analysis, Topology Optimization, Altair Hypermesh.

\section{Introduction}

In head-on collisions of bonnet-type cars (sedans, wagons, hatchbacks, etc., hereafter referred to simply as cars) and heavy trucks, the car often under runs the front of the truck, and the car crew received the serious or fatal injuries. The crash safety performance of the car depends on the way its structural parts interact with the structural parts of the truck. Front Underrun Protection Device equipment that prevents the car from under running the truck is obligatory in India. The Required strength and ground clearance of FUPDs are specified in the relevant regulations used in India. Accidents between cars and trucks are among the most fatal accidents because of the car under running. This phenomenon leads to serious and fatal injuries for car occupants because of intrusion of the car structure into the passenger compartment.

This has led to the development of test procedure for energy-absorbing front under run protection systems for trucks. There is a summary of accident analysis of several European countries, where we can read that of the 48000 fatally injured people in road traffic accidents in 1992, 13000 people were killed in accident with trucks involved, about 7000 were car occupants and 4200 of them were killed in car-to-truck frontal collisions.In the same time, in 1994, a collaboration in France between Renault VI (truck manufacturer) and INRETS has begun. The research program set up is based on a experimental design to determine the effect of the vehicle masses, the overlap and the closing speed and the effect of the Front Under run Protection Device on mechanical and biomechanical characteristics. This experimental design is presented which is also analysed and made available to use as a valid Front Under run Protection Device for trucks.

It is very common incident that during the accident a passenger vehicle going under the heavy commercial vehicle either from rear, front or side. During collision, there is a risk that the passenger vehicle will penetrate under (run under) the front or rear part of the truck and thus there are great chances of fatal injuries to the occupants of the passenger car. The study of such statistical data is done by Bjorsting Ulf. The Under-run Protection Device (UPD) is an attachment fixed to the heavy commercial vehicle which will avoid the under running of the passenger vehicles and further reduce the chances of severe fatal injuries to the passenger vehicle occupant. The design and the strength of the Front Under-run Protection Device (FUPD) should be such that it should take the impact load and avoid the under running of the passenger vehicle from the rear of the heavy commercial vehicle. The Indian Standard IS 14812-2005 specifies the requirements of the Front Underrun Protection Device. Physical testing is done with 5 impactors with specific load and sequence; hit the FUPD to evaluate its strength. This scenario is replicated using Finite Element (FE) solvers like Altair Radioss. The load taken by the Front Underrun Protection Device is evaluated using reaction forces. This virtual validation is important for cost saving in the tooling, repetitive testing of the vehicle and cost involved in the same.

II. Modeling Of Front Under Run Protection Device

Modelling of Front Underrun Protection Device is done with the help of a figure 1, NX8.0 software is used for designing the $3 \mathrm{~d}$ model for virtual analysis. All the dimensions are taken from above European 
standards.As per Indian rules and regulations this dimensions are little changed, approximate dimensions are took from figure 1.

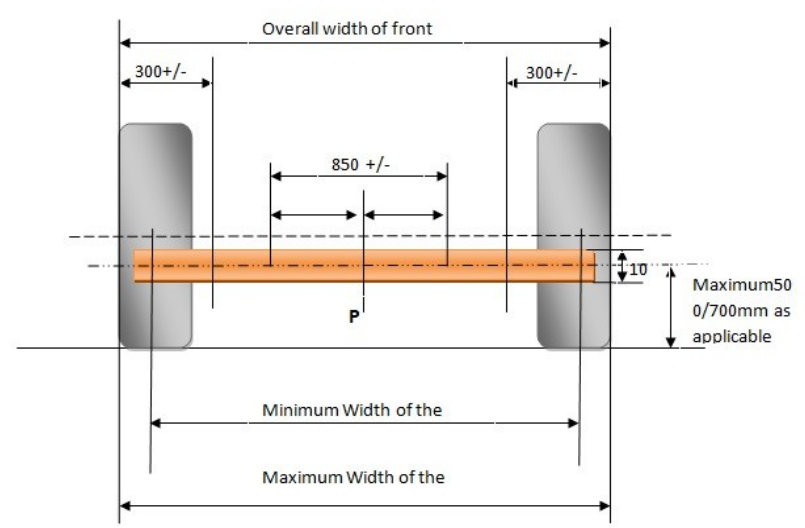

Fig. 1 Position of Front Under-run Protection Device and the Resistance Point P

roads.

As per figure 2 approximate dimensions Front Underrun Protection Device is designed for Indian

Now next step is to assemble each single part and put together and do test on Front Underrun Protection Device assembly. Complete assembly model is shown below for reference.Next step is to import 3d assembly model in to Pre-Processing software, using Ls Dyna Solver for doing Crash test and for visualization Post-Processing. Regarding complete methodology will be in detail below.

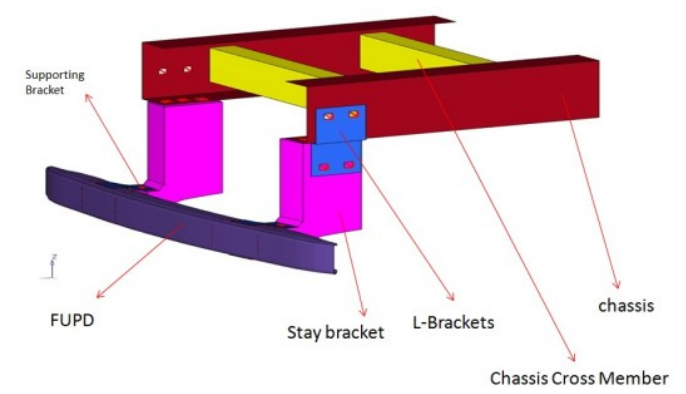

Fig .2 Complete assembly model which is designed using NX8.0

\section{PRE-PROCESSING OF FRONT UNDER RUN PROTECTION DEVICE}

Front under run protection device is a sheet metal component which will have thickness to each part. For that finite element method introduced a midsurface extraction to apply thickness. So midsurface had extracted for FUPD assembly component. Thickness is assigned to Fupd. Using Hypermesh interface generated Midsurface, Hypermesh is powerful to generate midsurface. In Hypermesh interface, just select complete solid and click on extract green button on right side. It will generate midsurface for FUPD, in model tree also it shows middle surface collector.

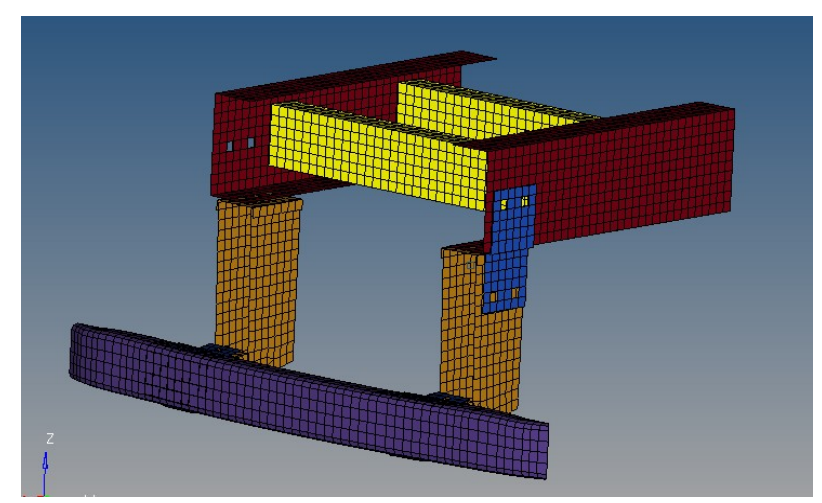

Fig. 3 Meshed model in Hypermesh interface 
For complete Front Underrun Protection Device assembly model it was meshed with the figure 3. Which gives quality mesh, for each single surface automesh panel is used. Hypermesh is powerful software where we can adjust the density of elements on edge. LS-DYNA is widely used by the automotive industry to analyze vehicle designs. LS-DYNA accurately predicts a car's behavior in a collision and the effects of the collision upon the car's occupants. With LS-DYNA, automotive companies and their suppliers can test car designs without having to tool or experimentally test a prototype, thus saving time and expense. Before solving Front Underrun Protection Device crash, material is required for Front Underrun Protection Device. Mild steel is used for complete Front Underrun Protection Device assembly.

Thickness is $1 \mathrm{~mm}$ for each sheet available in Front Underrun Protection Device and for the second model in between stay bracket supporting bracket is placed which is having $1.8 \mathrm{~mm}$ thickness and for third model stay bracket is completely covered. In Hypermesh $3 \mathrm{~d}$ element visualization option is available to see the thickness in $3 \mathrm{~d}$ view. Why this because for $2 \mathrm{~d}$ elements $1 \mathrm{~mm}$ thickness is assigned, the same thing showing in $3 \mathrm{~d}$ view. Boundary condition is nothing but constraint, here FUPD is fixed to chassis in all degrees of freedom. It means that those elements cannot move anywhere. When force is applied in the same direction these fixed elements will move. That is called degrees of freedom. Front under run Protection Device is tested for car occupant safety by performing Crash analysis with $800 \mathrm{~kg}$ (mass of the car) hitting the FUPD with velocity $5555 \mathrm{~mm} / \mathrm{s}$ which is around $20 \mathrm{~km} / \mathrm{hr}$ and friction is considered as 1 and analyzing its performance and changing design to improve the crash results. Here in virtual analysis method in the place of car we are taking a rigid wall as a car which is at $100 \mathrm{~mm}$ distance from the Front under run protection device for that we are giving initial velocity and solving for impact to FUPD. It is same like Car to FUPD,

\section{REDESIGN OF MODEL USING OPTIMIZATION}

Altair OptiStruct is an award winning CAE technology for conceptual design synthesis and structural optimization. OptiStruct uses the analysis capabilities of RADIOSS and Motion Solve to compute responses for optimization. Topology is a mathematical technique that optimized the material distribution for a structure within a given package space.Optimization is done to the Front underrun protection device model the steps of optimization technique are mentioned below.First step is user profile should change to Optistruct in hypermesh interface. Response for OptiStruct is any value or function that is dependent of the Design Variable and is evaluated during the solution.OptiStruct allows the use of numerous structural responses, calculated in a finite element analysis, or combinations of these responses to be used as objective and constraint functions in a structural optimization. Responses are defined using DRESP1 bulk data entries. Combinations of responses are defined using either DRESP2 entries, which reference an equation defined by a DEQATN bulk data entry, or DRESP3 entries, which make use of user-defined external routines identified by the LOADLIB I/O option. Responses are either global or subcase (loadstep, load case) related. The character of a response determines whether or not a constraint or objective referencing that particular response needs to be referenced within a subcase.

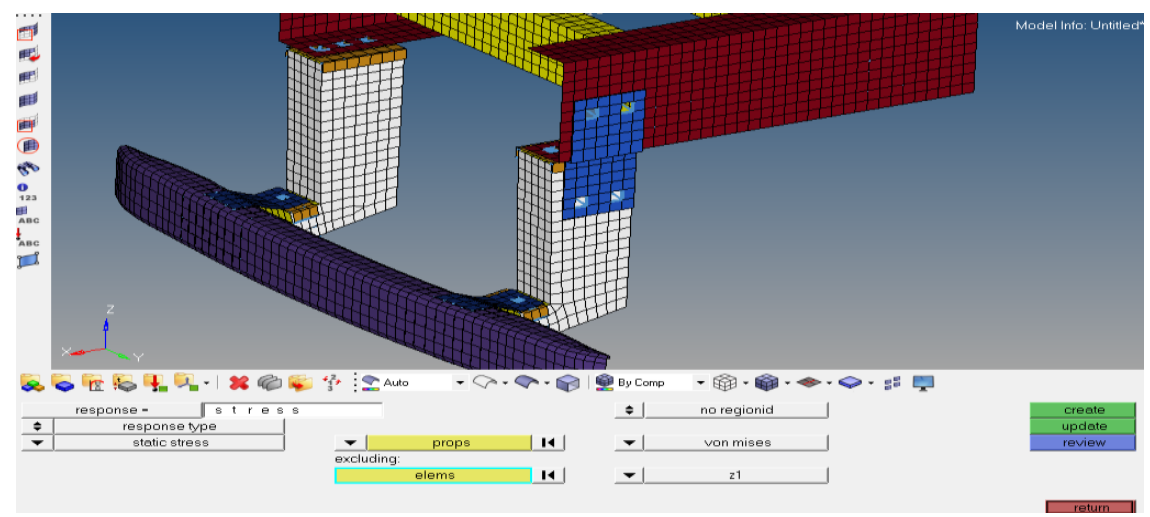

Fig.4 Stress Response is selected in topology optimization panel 


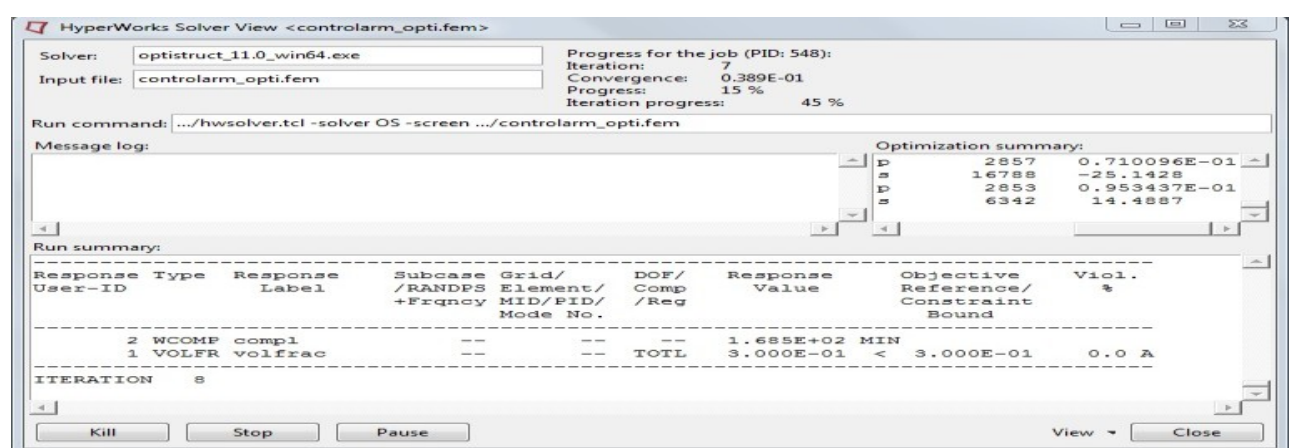

Fig. 5 Iteration process of Optistruct while running the solution

\section{RESULTS}

Hyperview is a Post processing tool, which is highly robust and easy to learn tool. In which displacement, stresses and strain can be visualize and animation video can be viewed with the help of Hyperview player. It's high performance $3 \mathrm{~d}$ graphics software. Here it supports all other solver result file which can be import in to Hyperview with the help of result file. Then based on output request it shows. For the Base model initial velocity is applied.

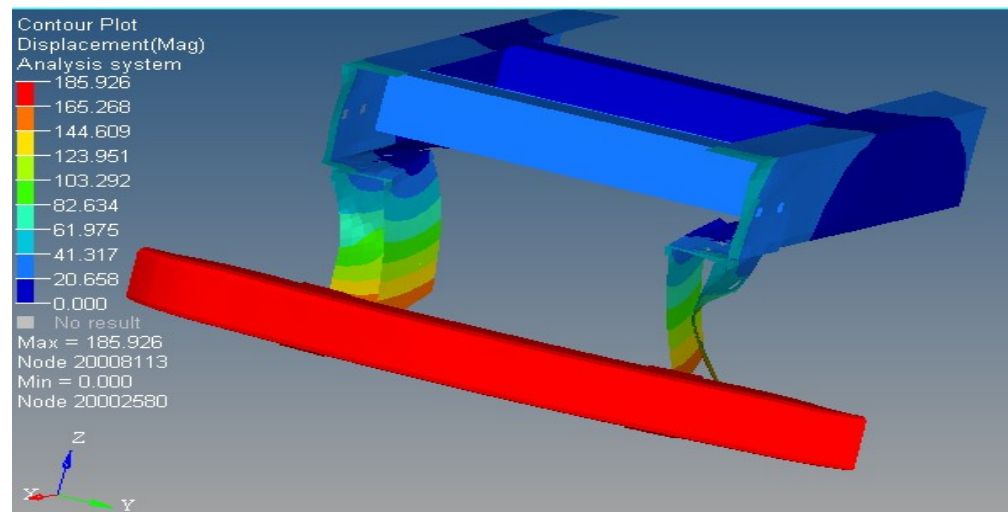

Fig. 6 Displacement Value $185 \mathrm{~mm}$ at 0.05 seconds

As per deformation of Front Underrun Protection Device of first base model shape is failed because it was displaced about $185 \mathrm{~mm}$ which is disturbing to Chassis. Chassis is affected very dangerously and who sits on the driver seat he will also affect with this type of displacement. to reduce the impact force on stay bracket we improved the design and done the analysis in the next level.
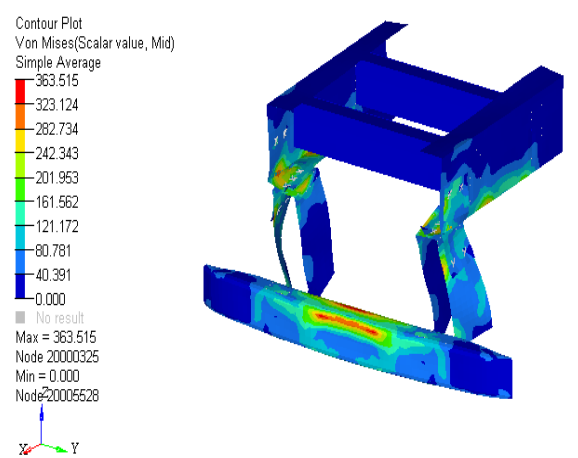

Fig. 7 Stress Value (227 MPA) at 0.05 seconds and 363 at 0.1 seconds

Stress is about 227 at 0.05 and at 0.1 seconds it is crossing the stress value limit so it was failed because Mild Steel material yield point is 350 to $450 \mathrm{MPA}$ around. So above stress value has crossed the yield point of Mild steel mechanical property. By this our first base model FUPD is failed. 


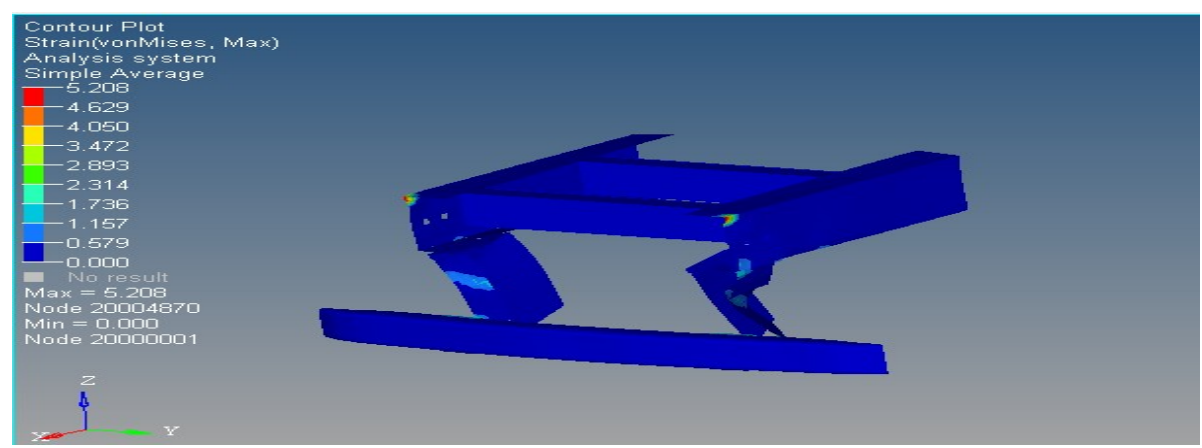

Fig. 8 Strain Value $(5.208 \mathrm{~mm})$ at 0.05 seconds

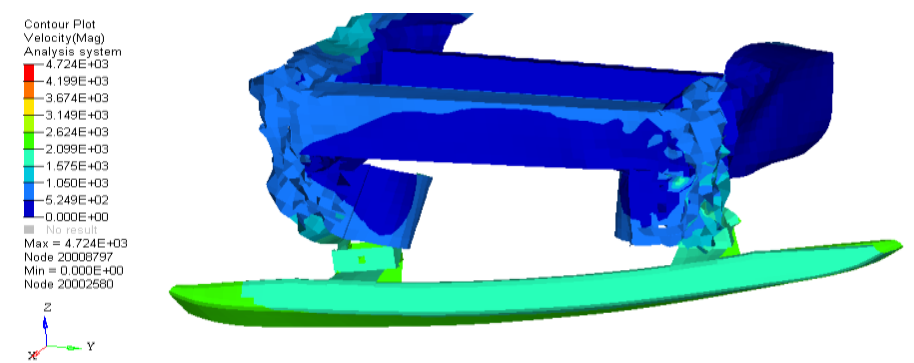

Fig. 9 Velocity Value $4.724 \mathrm{E}+03$ at 0.1 seconds

Stress value which is crossing the yield point of Mild steel material. So again by this value that proved mild steel for FUPD is failed due to high impact. Next is to design the new one and check the stress value. To improve the safety of passenger and FUPD strength.

If we compare the displacement values in the above figure first model is completely failing, second model is safe with displacement value is equal to $182 \mathrm{~mm}$. Third model is having displacement is $188 \mathrm{~mm}$. by this analysis we knows that the second model which is safe and better and Optimization is carried out to the third model to reduce the displacement values.

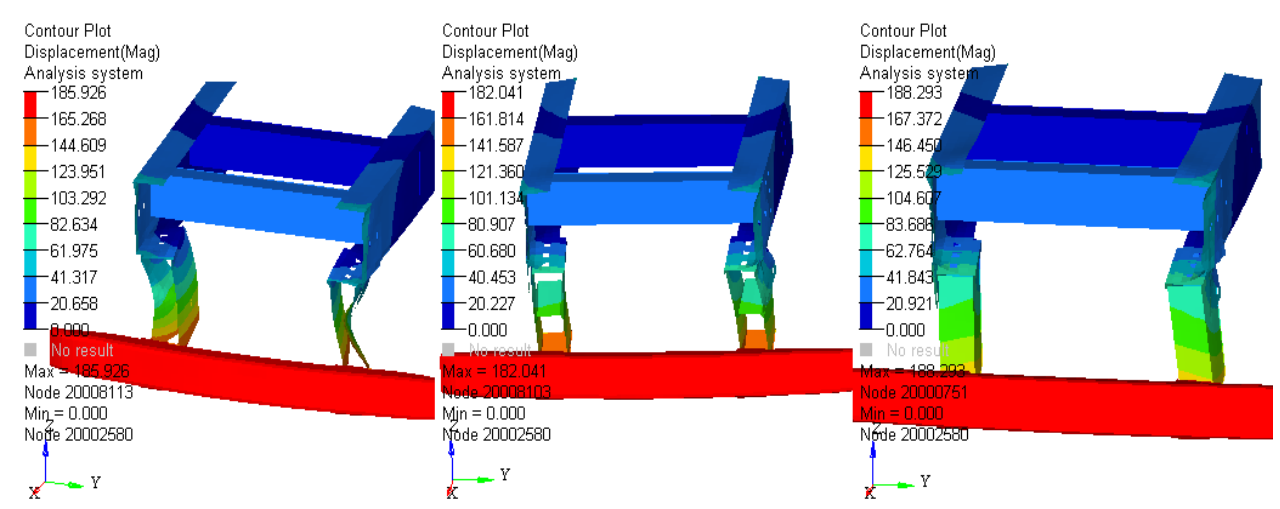

Fig. 10 Displacement vs three models which solved.

\section{Optimized Results} optimization.

Optimization is completed and results are taken 6 iterations to complete the thickness and topology 


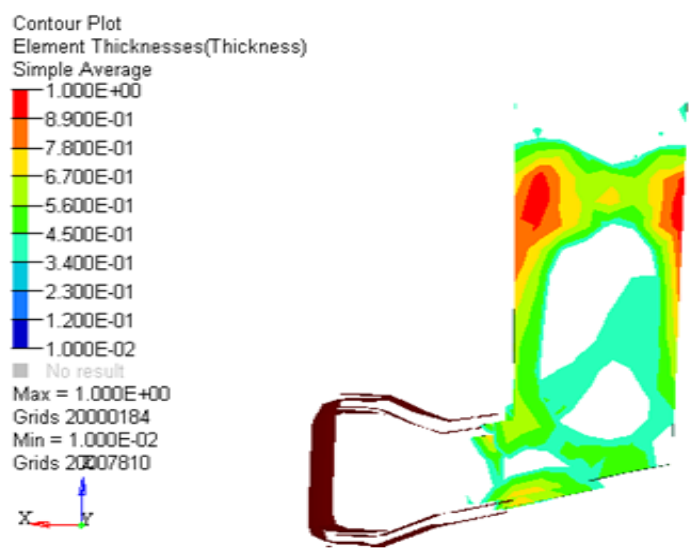

Fig. 11 Topology Optimization Results

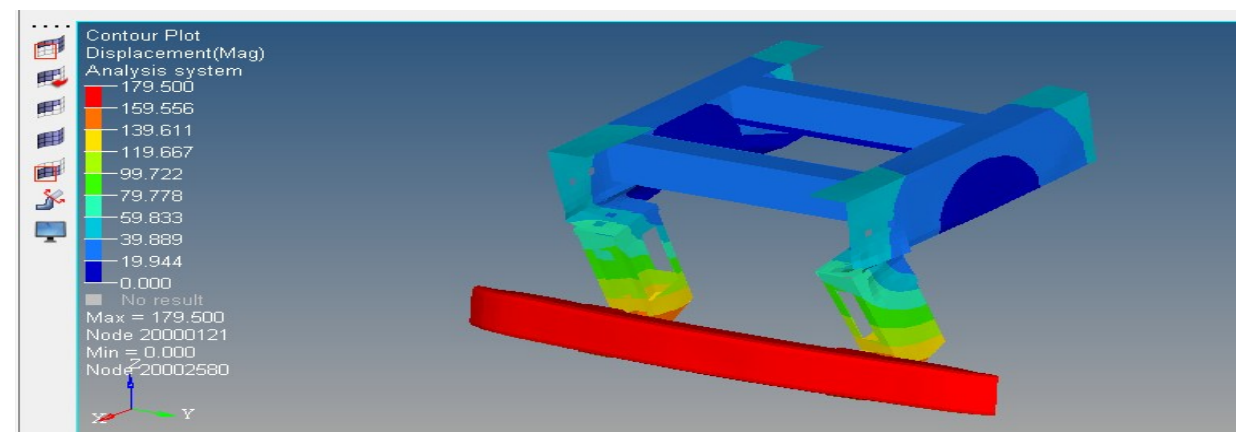

Fig. 12 Displacement of optimized model is $179 \mathrm{~mm}$

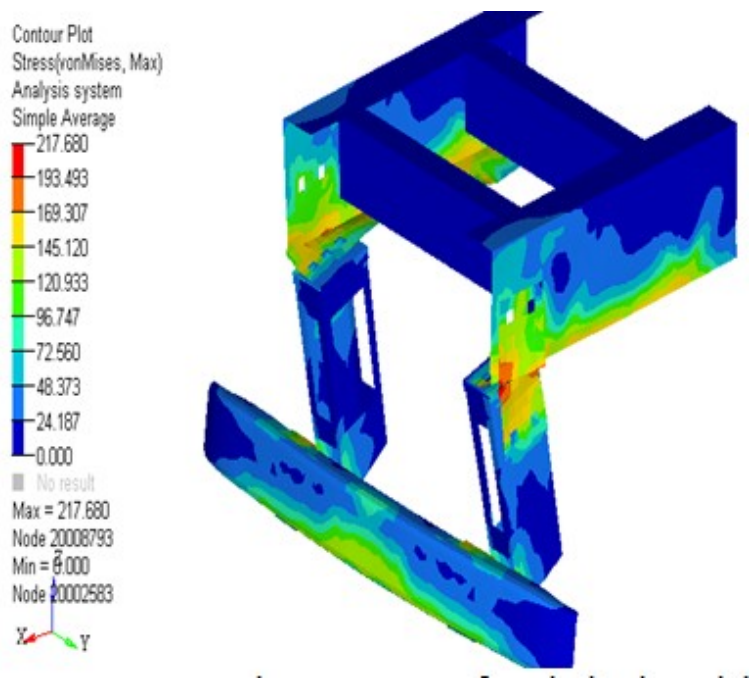

Fig. 13 Stress of optimized model is $217 \mathrm{MPA}$

Weight of the optimized and base third model comparison is shown below
6. elements

I elems IN
$C$ suraces
$r$ solids

\begin{tabular}{c||c} 
area $=$ & $2.836 \mathrm{e}+06$ \\
\hline volume $=$ & $2.836 \mathrm{e}+06$ \\
\hline total mass $=$ & $2.226 \mathrm{e}-02$
\end{tabular}

Fig. 14 Front Underrun Protection Device Model 3 mass is 22.26kgs. 


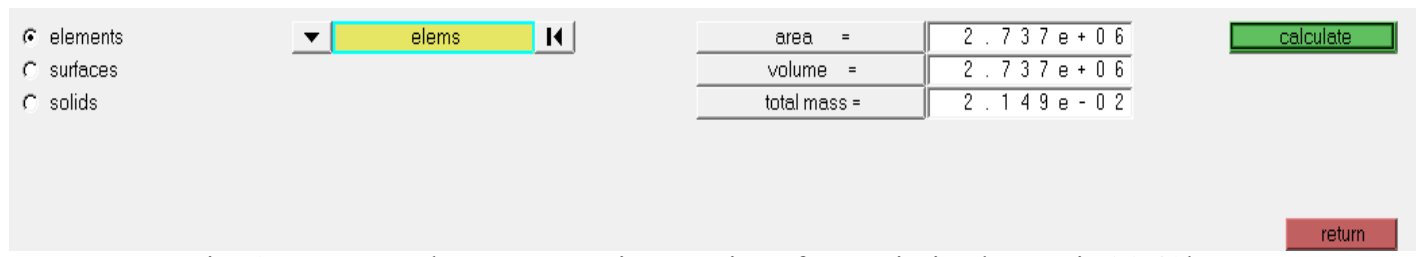

Fig. 15 Front Underrun Protection Device after optimized mass is $21.49 \mathrm{kgs}$.

Weight reduction achieved by optimization result is $6 \%$, compared to base third model. Finally we conclude that the optimized model results are less than the third design model. By this we can say that optimized front under run protection device is selected. Front under run protection is achieved less weight, less displacement and less stress so that for the passenger who are sitting in the car having high safety by placing this optimized model.

\section{Conclusions}

Head on collision contribute significant amount of serious accidents which causes driver fatalities. The car safety performances can work effectively by providing FUPD to the heavy trucks. The trucks with UPD can reduce the car driver fatalities by $40 \%$ In India, for Front Under-run Protection Device, IS 14812:2005 regulation is required in for the trucks to meet the safety requirement to protect under running of the passenger car. In above said design, the maximum displacement of FUPD bar is limited to $179 \mathrm{~mm}$ hence it meet the requirements as per IS 14812:2005. But this needs to be confirmed with physical testing in future. The virtual simulation is tool which can be used to avoid or reduce the physical testing of mechanical systems and components. Overall effect of this is cost saving and same is done with FUPD analysis.

As per above results optimized model is safe, more strength and low weight mode suits the best suggested design. Weight reduction achieved by optimization result is $6 \%$, compared to base third Model and displacement is about $5 \%$ and Stress is $6 \%$.Finally we conclude that the optimized model results are less than the third design model. By this we can say that optimized front under run protection device is selected. Front under run protection is achieved less weight, less displacement and less stress so that for the passenger who is sitting in the car having high safety by placing this optimized model. We can suggest to automobile industries to keep this type of Front Underrun Protection Device to truck, busses etc which saves the life of passenger with less injury.

\section{Acknowledgements}

First and foremost,I would like to express my deep sense of gratitude and indebtedness to my supervisor Dr.T.Ramamohan Rao for his encouragement, suggestions and support from an early stage of this research and providing me the extraordinary experiences throughout the work Above all, his priceless and meticulous supervision at each and every phase of work inspired me in innumerable ways.

\section{References}

[1] Jim Anderson CIC, Cranfield Impact Centre, UK, Johann Gwehenberger GDV, Institute for

Vehicle Safety, Munich, DE, JenöBende GDV, Institute for Vehicle Safety, Munich, DE FlorisLeneman TNO Automotive, NL "Truck/Trailer Compatibility with Cars and Related Topics from VC-COMPAT"

[2] Matej Glavac, Univ.Dipl.-Ing., Prof. Dr. Zoran Ren University of Maribor, Faculty of Mechanical Engineering "Computational Approval for Rear Under Run Protection Device with MSC. Nastran” 2001126

[3] "Safety inspection of rear underrun protection device in Slovenia (No. 58.01)", Uradni list RepublikeSlovenije, No. 3, 20.1.1995, p. $182-183$

[4] Liu Hong-Fei and Peng Tao Xu Hong-Guo, Tan Li-dong and Su Li-li College of Transportation University of Jilin, Changchun, Jilin province, China "Research on the Intelligent Rear Under-run Protection

System for Trucks" Proceedings of the 8th World Congress on Intelligent Control and Automation July 6-9 2010, Jinan, China

[5] Kaustubh Joshi, T.A. Jadhav, Ashok Joshi "Finite Element Analysis of Rear Under-Run Protection Device (RUPD) for Impact Loading" International Journal of Engineering Research and Development ISSN: 2278- 067X, Volume 1, Issue 7 (June 2012), PP.19-26 www.ijerd.com

[6] Zou R., Rechnitzer G., Grzebieta R. "Simulation of Truck Rear Underrun Barrier Impact", 17th International Technical Conference on the Enhanced Safety of Vehicles, Amsterdam, June 4-7, 2001.

[7] Muxi LEI,Zhengbao LEI, Shubin WEI,YonghanLI "Geometry optimization design for crank-slider-CST type low rear protection device of truck”978-1-61284-459-6/11/C2011 IEEE

[8] Nitin S Gokhale "Practical Finite Element Analysis" Finite to infinite,Pune.

[9]. Bjornstig J, Bjornstig Ulf, Eriksson A, "Passenger car collision fatalities - With special emphasis on collision with heavy vehicles", Accident Analysis and Prevention 2008, P 158-166. 